\title{
A new species of Tephritis Latreille (Diptera: Tephritidae) from Iran
}

\author{
Saeed Mohamadzade Namin
}

Mohamadzade Namin, S. 2011: A new species of Tephritis Latreille (Diptera: Tephritidae) from Iran. — Entomol. Fennica 22: 284-288.

Tephritis nozarii sp. n. from East Azerbaijan Province (North West of Iran) is described and illustrated. It is similar to T. hendeliana Hering, T. hyosciami Linnaeus and T. multiguttata Becker in its pale brownish grey wing pattern, differing by the number of hyaline spots in marginal part of $r_{1}$ cell and some other details of pattern. Cell $\mathrm{r}_{1}$ in $T$. nozarii $\mathbf{s p .}$. n. contains 3 subequally large spots (resembling some Campiglossa species), a character rarely encountered in Tephritis.

S. Mohamadzade Namin, Young Researchers Club, Varamin-Pishva Branch, Is-
lamic Azad University, Varamin, Iran; E-mail: mohamadzade@iauvaramin.
ac.ir

Received 14 June 2011, accepted 31 August 2011

\section{Introduction}

With about 120 species (Norrbom et al. 1999, Korneyev \& Dirlbek 2000, Freidberg \& Kutuk 2002, Kutuk 2008), Tephritis Latreille is the largest genus of Tephritidae in the Palaearctic Region. Most species of Tephritis infest the flowerheads of Asteraceae hosts of several tribes, with or without the induction of galls. A few species induce formation of galls in the upper or subterranean parts of stems of Asteraceae (Freidberg 1984).

Tephritis are small to medium-sized flies, which can be recognized by the combination of the following characters: proboscis capitate; 2 frontal and 2 orbital setae present; posterior orbital (except in $T$. arnicae Linnaeus) and lateral vertical setae whitish and acuminate; postocular setae whitish and lanceolate; posterior notopleural seta white (except in T. conura Loew and $T$. arnicae); anepisternal, katepisternal and anepisternal usually concolorous with most setae, other setae brownish or blackish; dorsocentral seta on or slightly posterior to transverse suture; scutellum with 2 pairs of setae, apical seta about $0.5-0.6$ times as long as basal seta. Wing with reticulate pattern, highly variable among the species, usually with 2 large and one small hyaline spots in cell $r_{1}$ and 2 dark bars divergent to apices of veins $\mathrm{R}_{4+5}$ and $\mathrm{M}$, or with these spots isolated from the rest of the markings; cell bcu with short posteroapical extension. Abdomen commonly microtrichose, usually whitish setulose (in a few species widely shining and/or with black setulae); epandrium oval, with 2 small subequal prensisetae; glans elongate and weakly sclerotized, with membranous part (sometimes called vesica) about as long as basal sclerotized part, differing mainly by wider or narrower outlines among species; oviscape somewhat flattened dorsoventrally, with shape of its apex often speciesspecific; 2 spermathecae, elongate oval to pearshaped in different species (Merz 1994, Freidberg \& Kutuk 2002, S. Korneyev, pers. comm.).

During the study of tephritid flies in the fauna of Azerbaijan region (NW Iran) in 2009-2011, a previously unknown species of the genus Tephritis was collected on flower heads of Cir- 
sium sp. (Asteraceae). The new species is described and figured below.

\section{Material and methods}

The examined material was minuten-pinned and deposited in collections of the following institutions:

- JAZM, Jalal Afashar Zoological Museum, College of Agriculture, University of Tehran, Karaj, Iran

- SIZK, I. I. Schmalhausen Institute of Zoology, National Academy of Sciences of Ukraine, Kiev, Ukraine

- Author's personal collection.

Morphological terminology follows White et al. (1999). The following morphometric characters with their abbreviations are used: Body length $(\mathrm{BL})$, Wing length (WL), Aculeus length (AL), Dorsal length of oviscape (DOL) and Ventral length of oviscape (VOL).

\section{Description of Tephritis nozarii Mohamadzade Namin sp. $n$. (Figs. 1-3)}

Type material. Holotype (female): Iran: East Azerbaijan province, $30 \mathrm{~km}$ SE Tabriz, Sahand Mountain, 2,900 m a.s.1., 30.VIII.2010, swept from Cirsium sp., Mohamadzade and Najarpoor leg. (JAZM).

Paratypes: $2 \hat{\jmath}, 3$, same collection data as in holotype; 19 , Ardabil Province, Sabalan Mountain, 2,500 $\mathrm{m}$ a.s.1.; 28.VIII.2010, swept from Cirsium sp.; 1엉 West Azerbaijan province, $3 \mathrm{~km}$ west Ziveh, 2,500 m a.s.1., 25.V.2011, swept from Cirsium sp., (Mohamadzade and Najarpoor leg.) (some paratypes are deposited also in SIZK and author's personal collection).

Description. Head: Yellowish. Length: height: width ratio $=1: 1.15: 1.47$. Ocellar spot, mark on upper part of occiput and slender part of arista black. Antennae yellow, scape covered with densely black setulae. Face whitish yellow. First flagellomere rounded antro-ventraly and 1.6 times as long as wide. Frons as wide as eye. Com- pound eye 1.3 times as high as long. Gena 0.5 times as high as length of first flagellomere. Ocellar, median vertical, anterior orbital and frontal setae dark brown and acuminate; genal seta pale brown and acuminate; remaining setae whitish or yellowish and lanceolate; setulae on anterior part of gena, distal part of palpus and on pedicel brownish; remaining setulae whitish (Figs. 1b, 2b).

Thorax: Ground color black, covered with gray microtomentum. Postpronotal lobe, dorsal margin of anepisternum, posterior part of notopleural area around posterior notopleural seta and scutellum margin yellow. Basal part of scutellum dark brown and the area between scutellar setae brownish. Dorsocentral seta situated slightly posterior to transverse suture. Most setae dark brown and acuminate; posterior notopleural seta yellowish and lanceolate; setulae whitish. Anteriour scutellar setae 0.45 times as long as posterior ones (Fig. 1c). Halter yellow.

Wing: Wing pattern reticulated, pale brown, base of wing hyaline. Stigma yellowish. Cell $r_{1}$ with three subequal hyaline spots distally of $\mathrm{R}_{1}$ apex; cell $r_{2+3}$ basally hyaline, in distal 0.8 pale brown, with 3 hyaline spot in middle portion and connected with hyaline spots in cell $r_{1}$ and 2 apical spots, both of them connected with 2 subapical hyaline spots in $\mathrm{r}_{4+5}$ cell. Cell br hyaline, in distal $1 / 3$ pale brown with $3-4$ hyaline spots and 2 partly confluent dots aligned to $\mathrm{r}-\mathrm{m}$ crossvein. Cell $r_{4+5}$ with 2 partly confluent dots aligned to $\mathrm{r}-\mathrm{m}$ crossvein, elongate trapezoid or subrectangular spot as wide as cell and 7 hyaline spots apical of them. Apical spot bordered by 2 moderately wide apical rays joined to remaining dark pattern in middle of cell $\mathrm{r}_{4+5}$ and along vein M. Cell $\mathrm{dm}$ hyaline in basal $1 / 4$ and with 5-6 hyaline spots in distal portion. Cell $\mathrm{m}$ with 5 separate large oval hyaline spots; apical spot narrowly touching subapical hyaline spot in $\mathrm{r}_{4+5}$ cell. Cell cua brown in anterior part of longitudinal fold, with 3 large and 2 apical small hyaline spots. Wing pattern with two grey bars extending into anal cell. Vein $R_{4+5}$ with $0-2$ setulae ventrally (Figs. 1a, 2a).

Legs: Brownish yellow with black setulae. Fore femur with two dorsal and one ventral rows of setae. Mid tibia with long black spur ventroapicaly. 


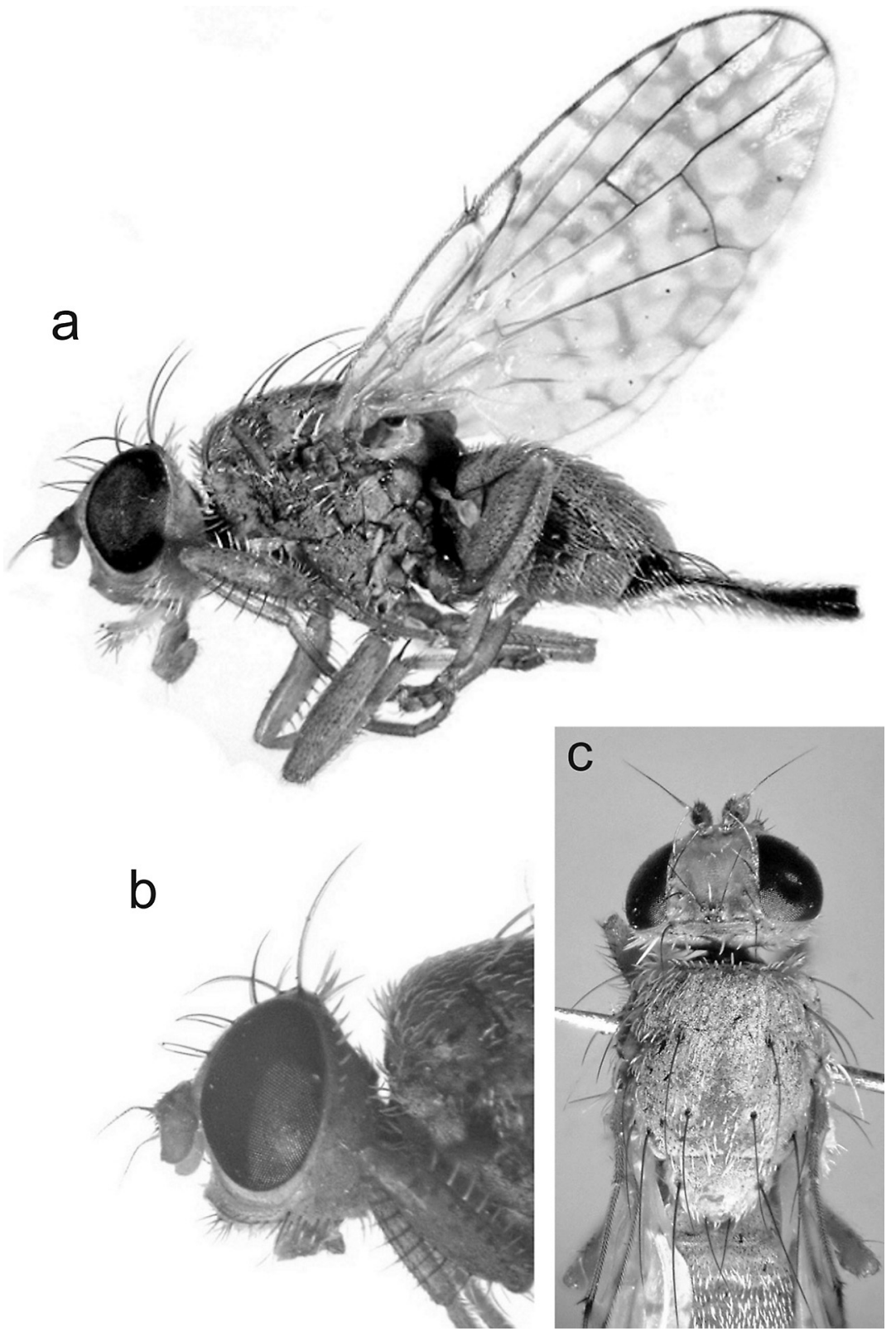

Fig. 1. Tephritis nozarii sp. n. - a. Female (Holotype), total view, left. - b. Male, head, left. - c. Female (Holotype), mesonotum.
Abdomen: Ground color black, very sparsely greyish microtrichose and whitish setulose. Hind margin of tergite 6 in female and tergite 5 in male with long brown setae. Male genitalia similar to other Tephritis species, phallus without spurs on preglans; glans (Fig. 3) very slender, mostly membranous. Oviscape shiny black with a few whitish setae at basal 1/3 dorsally and ventrally. Oviscape about as long as preceding 4 abdominal tergites. Aculeus moderately narrow, 6.5 times as long as wide, apically rounded, without preapical steps, as in Figs. 2c-d. Spermathecae as in Fig. 2e, elongate oval, 3.7 times as long as wide.

Measurements: ${ }^{\lambda}$ : $\mathrm{BL}=4.2-4.6 \mathrm{~mm} ; \mathrm{WL}=$ 4-4.3 mm; $q$ : $\mathrm{BL}=5.2-5.7 ; \mathrm{WL}=4.2-4.6 \mathrm{~mm}$; $\mathrm{DLO}=1.2-1.4 \mathrm{~mm} ; \mathrm{VLO}=1.4-1.6 \mathrm{~mm} ; \mathrm{AL}=$ $1.6-1.7 \mathrm{~mm}$.

Etymology. The species is named after Dr. Jamasb Nozari, in recognition of his valuable contribution into study of Iranian Lepidoptera. 


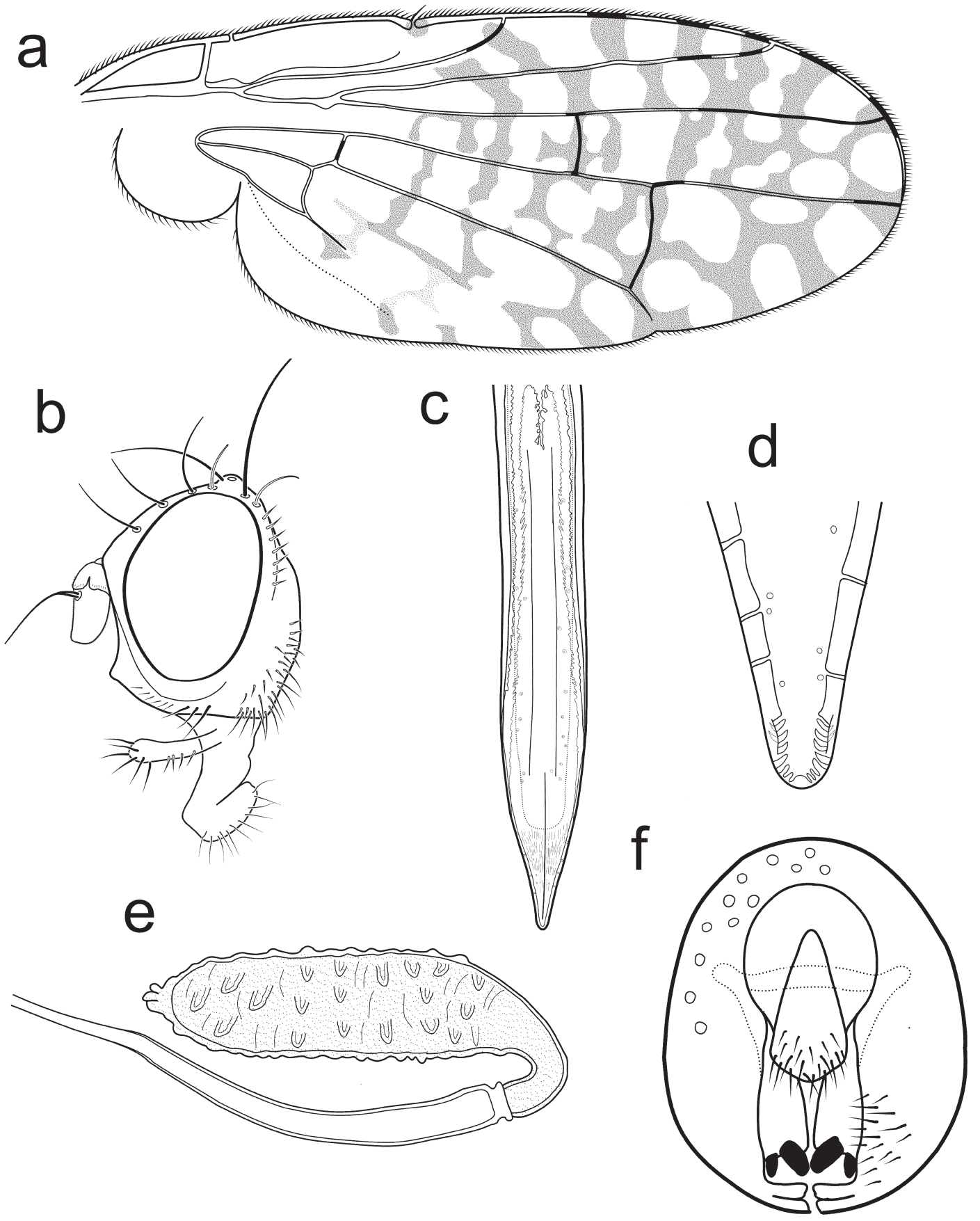

Fig. 2. Tephritis nozarii sp. n. - a. Wing pattern. - b. Head. - c. Aculeus. - d. Aculeus tip. - e. Spermathecae. - f. Epandrium.

\section{Discussion}

Tephritis nozarii $\mathbf{s p .}$ n. superficially resembles some species of the genus Campiglossa Rondani in having 3 subequal hyaline spots in the $r_{1}$ cell (e.g., C. contingens Becker, C. ignobilis Loew) differing by that character from all known Palaearctic species of Tephritis. It, however, clearly belongs to the genus Tephritis based on the structure of phallus glans, bearing no sclerotized parts in its 

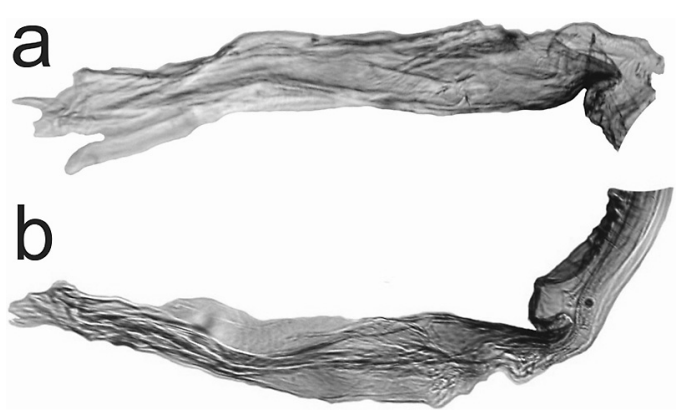

Fig. 3. Glans of Tephritis nozarii sp. n. - a. Ventral view. - b. Lateral view.

apical half (with complex sclerotized tubular structures in Campiglossa species).

The new species shares similar body and wing size and coloration (first of all, moderately long oviscape with white setulae, aculeus apex without steps or incisions, and crossvein r-m surrounded with hyaline spots and first large hyaline spot in cell $\mathrm{r}_{4+5}$ as wide as cell and the host plant of the subtribe Carduinae) with the widespread European species T. hyosciami (Linnaeus, 1758) and T. hendeliana Hering, 1944, differing by wing apex with 2 entire dark rays and cell $r_{1}$ with 3 subequal hyaline spots (in T. hyosciami and $T$. hendeliana apex with 2 apical dark spots separated from dark wing pattern and cell $r_{1}$ with 2 subequal spots).

Among Middle East species of Tephritis, the new species is similar to T. multiguttata Becker, in its pale gray reticulate wing pattern, differing by 3 hyaline spots in $r_{1}$ cell ( 2 large hyaline spots in T. multiguttata), crossvein $\mathrm{r}-\mathrm{m}$ with 4 hyaline spots aligned (in T. multiguttata entirely in dark field) and by the oviscape as long as preceding 4 abdominal tergites (in T. multiguttata as long as preceding 2 abdominal tergites).
Acknowledgments. I wish to express my sincere thanks to Dr. Valery A. Korneyev (Schmalhausen Institute of Zoology, National Academy of Sciences of Ukraine, Kiev, Ukraine) for reading early versions of this manuscript and useful critical comments. I thank also Mrs. Arezoo Najarpoor (MSc student of Entomology at University of Tehran) for her help to the author during fieldwork in East Azerbaijan Province. I also thank two anonymous referees for their valuable comments and criticism. This study was supported by Islamic Azad University, Varamin-Pishva branch.

\section{References}

Freidberg, A. 1984: Gall Tephritidae (Diptera). - In: Ananthakrishnan, T. N. (ed.), Biology of gall insects: 129-167. Oxford \& IBH, New Delhi. 362 pp.

Freidberg, A. \& Kutuk, M. 2002: A new apecies of Tephritis from Turkey, with a key to the species of the Tephritis pulchra group. - Israel Journal of Zoology 48: 295-311.

Korneyev, V. A. \& Dirlbek, J. 2000: The fruit flies (Diptera: Tephritidae) of Syria, Jordan and Iraq. - Studia dipterologica 7: 463-482.

Kutuk, M. 2008: A new species of Tephritis Latreille (Diptera: Tephritidae) from Turkey. - Belgian Journal of Zoology 138: 132-134.

Merz, B. 1994: A revision of the western Palaearctic species of Tephritis (Diptera, Tephritidae). - In: O'Hara, J. F. (ed.), Third International Congress of Dipterology: 151-152. 15-19 August 1994. University of Guelph, Guelph. 270 pp.

Norrbom, A. L., Carroll, L. E., Thompson, F. C., White, I. M. \& Freidberg, A. 1999: Systematic Database of Names. - In: Thompson, F. C. (ed.), Fruit Fly Expert Identification System and Systematic Information Database: 65-299. Myia (1998). 524 pp.

White, I. M., Headrick, D. H., Norrbom, A. L. \& Carroll, L. E. 1999: Glossary. — In: Aluja, M. \& Norrbom, A. L. (eds.), Fruit Flies (Tephritidae): Phylogeny and Evolution of Behavior: 881-924. CRC Press, Boca Raton. 963 pp. 